\title{
Epicardial propranolol administration for ventricular arrhythmias in dogs: matrix formulation and characterization
}

\begin{abstract}
Rivka Siden, William E. Flowers and Robert J. Levy
Department of Pediatrics, University of Michigan Medical School and Department of Pharmaceutics, College of Pharmacy, University of Michigan, Ann Arbor, MI, USA

The effect of propranolol on the prevention of ventricular tachycardia/fibrillation (VT/VF) due to acute coronary ischaemia was studied in dogs. A series of propranolol-polymer controlled release matrices in slab configuration using various polyurethanes and a polyurethane-silicone rubber copolymer were formulated and characterized. In general, drug release in vitro occurred with an initial burst phase followed by an exponentially declining delivery rate; the silicone rubber containing copolymer preparation had more sustained release properties than did pure polyurethane matrices. In the animal studies, dogs underwent 5 -hourly $10 \mathrm{~min}$ complete occlusions of the left anterior descending coronary artery (LAD), followed by 50 min normal perfusion. During non-drug occlusions VT occurred at a frequency of $1.22 \pm 0.12$ episodes $/ \mathrm{min}$. A propranolol-polyurethane matrix $(30 \% \mathrm{w} / \mathrm{w}, 28-42 \mathrm{mg})$ was placed on the ischaemic zone of the left ventricular epicardium immediately after the fifth occlusion. After an hour of drug delivery a sixth occlusion took place. The number of arrhythmia episodes both before and after drug were quantified and compared. The time to ventricular fibrillation (when present) and the mean blood pressure were also assessed. The drug patch delivered propranolol at a dose of $140 \pm 45 \mu \mathrm{g} / \mathrm{kg}$ by the conclusion of the $1 \mathrm{~h}$ study period. Therapeutic drug levels were achieved in the peripheral blood samples $(8.7-43.7 \mathrm{ng} / \mathrm{ml})$ and were enhanced in coronary venous samples $(360.9-556.2 \mathrm{ng} / \mathrm{ml})$. Reduction of blood pressure and proarrhythmic events following epicardial controlled release propranolol administration were noted but were not statistically significant. Arrhythmia episodes before and after propranolol were not found to be significantly different (VT/min $1.02 \pm 0.31$ and $1.22 \pm 0.12$ ). The occlusion time until VF occurred was also not significantly different before versus after propranolol ( $t=5.38 \pm 0.86$ and $5.28 \pm 0.48 \mathrm{~min}$ ). Therefore, despite attaining clinically therapeutic plasma levels, epicardial administration of propranolol was not found to be effective for the prevention of VT/VF due to acute ischaemia.
\end{abstract}

Keywords: Drug delivery, sustained release, $\beta$-blockers

Received 28 August 1991; revised 16 January 1992; accepted 28 January 1992

Ventricular arrhythmias are the most frequent cause of morbidity and mortality among patients with coronary heart disease ${ }^{1-3}$. Sustained ventricular tachycardia (VT) and ventricular fibrillation (VF) occurring after myocardial infarction are common and life threatening ${ }^{\mathbf{1}}$. A variety of antiarrhythmic drugs are available for the management of ventricular arrhythmias ${ }^{1,3-5}$. However, all of these agents have limitations. Undesirable characteristics such as narrow therapeutic indices ${ }^{1,4}$, cardiac and extracardiac side-effects ${ }^{3-5}$, and proarrhythmic potential ${ }^{6}$, limit the doses that can be administered systemically, thus complicating the treatment. When combination therapy is used, there is a potential for hazardous drug interactions ${ }^{7}$.

Correspondence to Dr Robert J. Levy, University of Michigan, Department of Pediatrics, R5014 Kresge II 0576, Ann Arbor, MI 48109, USA.
Since bolh the current pharmacological and the nonpharmacological treatments for ventricular arrhythmias are often ineffective and even dangerous, there is still need for an improved long-term therapeutic approach. A novel approach is the administration of the antiarrhythmic drugs directly to the myocardium by implantable controlled release drug delivery systems ${ }^{8-11}$.

Prior work has demonstrated that local controlled release administration of antiarrhythmic drugs using several different dog models was effective. For example, formulating a lidocaine-polyurethane controlled release matrix and implanting this drug delivery system on to the epicardium was found to be effective in converting ouabain-induced ventricular tachycardia in dogs to sinus $\mathrm{rhythm}^{\mathrm{B}}$. Both lidocaine and procainamide polyurethane matrices were found effective for converting ventricular tachycardia induced by rapid ventricular pacing to sinus 
rhythm. Allowing those matrices to remain on the heart muscle for $4 \mathrm{~h}$ resulted in a ventricular tachycardia electrical induction threshold elevation that demonstrated a prolonged effect of those antiarrhythmic drugs ${ }^{9,10}$. A verapamil-polyurethane matrix system was also found to be effective for reducing the number of VT/VF episodes due to a complete occlusion of the left anterior descending coronary artery (LAD) in dogs ${ }^{11}$.

The doses of the antiarrhythmic drugs in all the above studies were significantly lower than conventional systemic doses. Coronary blood levels were found to he in the therapeutic range while peripheral blood levels, when detectable, were far below the therapeutic or the toxic range $\mathrm{e}^{\mathrm{B}-11}$. These results demonstrate the ability to treat ventricular arrhythmias by transmyocardial drug administration in experimental models. This route of administration has also been shown to optimize efficacy by enhancing local therapeutic concentrations, while minimizing general toxicity due to elevated plasma levels.

Controlled release matrices for the delivery of drugs locally to the heart were found to be effective in several other disease processes. For example, local delivery of gentamicin has made possible the prevention of bacterial endocarditis in a dog model ${ }^{12}$. Other studies have demonstrated the efficacy of both site-specific controlled release dexamethasone for the inhibition of fibrous tissue build-up near a pacing catheter ${ }^{13}$, and diphosphonate matrix placement next to bioprosthetic heart valve leaflet implants for the prevention of calcification $^{14}$

Controlled release of $\beta$-adrenergic antagonists has not been investigated for antiarrhythmia therapy. $\beta$-Adrenergic blockers have been classified as Type II antiarrhythmic drugs $^{15}$. Currently $\beta$-adrenergic blockers are not first-line clinical agents for the treatment of any specific ventricular arrhythmia except in cases where the arrhythmia is associated with elevated catecholamine levels ${ }^{4.5}$

However, the use of $\beta$-adrenergic blockers is well established in the treatment of atrial arrhythmias ${ }^{4,5,16}$ Furthermore, a number of clinical studies have demonstrated that administration of $\beta$-blockers prophylactically to patients after myocardial infarction can reduce cardiac mortality ${ }^{1,4,5,17}$, presumably due to preventing ventricular arrhythmias during subsequent ischaemic episodes. Other clinical studies have indicated that the $\beta$ adrenergic blockers can be useful in the treatment of benign or potentially fatal ventricular arrhythmias ${ }^{18}$, treating patients with sustained ventricular tachyarrhythmias ${ }^{19}$, and preventing sudden death ${ }^{20-22}$.

A study that examined the effects of either timolol or propranolol on inducible sustained tachyarrhythmias in dogs found that both these $\beta$-blockers drugs were effective in abolishing inducible VT or VF in the dog with myocardial infarction ${ }^{23}$. Work by others using acute ischaemia models in $\operatorname{dogs}^{24-26}$ has also demonstrated that systemic administration of propranolol reduced the incidence of ventricular arrhythmias. Thus, both the clinical and the animal studies of the $\beta$-adrenergic blockers have established their potential usefulness in treating ventricular arrhythmias.

In the present study propranolol, a non-specific moderately potent $\beta$-blocker, served as a model drug for studying the effect of $\beta$-blockers on the ischaemic heart, when administered locally, directly to the myocardium via a controlled release matrix. The objectives of this study were:

1. To formulate and characterize the in vitro release profile of propranolol from various polymeric matrix preparations and to choose a suitable matrix for in vivo studies.

2. To study the pharmacological effects of the propranolol matrix in vivo for inhibition of ventricular arrhythmias in an ischaemic model in dogs.

3. To examine and compare coronary and peripheral propranolol blood levels during controlled release epicardial drug delivery.

\section{EXPERIMENTAL}

\section{Materials}

Propranolol hydrochloride and quinidine (HPLC internal standard) were obtained from Aldrich Chemical Corp. (Milwaukee, WI, USA). Two proprietary polyether (polytetramethylene glycol) polyurethanes MPU-5 (Matrix Media Inc., Wheat Ridge, CO, USA) and Biomer (Ethicon, Somerville, NJ, USA) were used, as $25 \%$ and $30 \%$ in dimethylacetamide. A proprietary polyurethanesilicone rubber copolymer 6605-41 (Dow Corning Corp. Midland, MI, USA] was also used for preparing drug matrices. HPLC grade acetonitrile and methanol were obtaincd from Mallinckrodt Inc. (Paris, KY, USA). HPLC grade ether and phosphoric acid $(85 \%)$ were obtained from Fisher Scientific (Pittsburgh, PA, USA). Dimethyacetamide (DMA) and ascorbic acid were purchased from Sigma (St Louis, MO, USA).

\section{Apparatus}

Electrocardiograms were continuously recorded on a Hewlett-Packard 3698A Instrumentation Recorder (Andover, MA, USA), displayed on AST premium 286 computer (AST Research Inc., Irvin, CA, USA), using a Codas analog to digital conversion board plus software (Data Q Instruments Inc., Akron, OH, USA). Periodically physiological readings were also produced using a pressurized ink system (Hewlett-Packard, Model PDRHP). A programmable stimulator (Grass Instruments, Model S88, Quincy, MA, USA) coupled to an optically isolated constant current source (Bloom Associated Ltd Reading, PA, USA) were used for pacing. Propranolol assays were carried out with a high-performance liquid chromatograph (Waters 501 HPLC Pump, Waters Inc. Milford, MA, USA] with a Waters 680 Automatic Gradient Controller which was equipped with a prepacked C18 precolumn (Waters Inc.) and an Altex UltrasphericODS, $25 \mathrm{~cm} \times 4.6 \mathrm{~mm}$ column (Beckman Inc., San Ramon, CA, USA). The detection of the drug was carried out with a Waters 470 scanning fluorescent detector and chromatograms were received on a Waters 740 Data Module (Waters Inc.).

\section{METHODS}

\section{Matrix formulation and in vitro release studies}

Propranolol hydrochloride matrices were prepared by dissolving the drug in DMA and adding the polymer of 
interest already dissolved in DMA. The mixture was then poured into Teflon ${ }^{\otimes}$ coated Petri dishes (10 cm diameter) and were dried in a vacuum oven at $50^{\circ} \mathrm{C}$ for $48 \mathrm{~h}$. Propranolol polymer films were cut into $1 \times 1 \mathrm{~cm}$ (200 $\mu \mathrm{m}$ thick) squares for in vitro release, in triplicate, using $0.05 \mathrm{mM}$ phosphate buffer under perfect sink conditions $\left(20 \mathrm{ml}\right.$ volumes at $\mathrm{pH} 7.4,37^{\circ} \mathrm{C}, 45 \mathrm{rev} \mathrm{min}{ }^{-1}$ changed daily]. Propranolol release was quantitated by UV absorbance $\left(\lambda_{\max }=289 \mathrm{~nm}\right)$. The calibration curve was found to be linear in the range that was used (5$100 \mu \mathrm{l} / \mathrm{ml}$ ).

\section{Stability test}

To assess the stability of propranolol during the in vitro release study and storage periods, six solutions in a concentration range $5-100 \mathrm{ng} / \mathrm{ml}$ were prepared, divided into groups and stored at 4 and $37^{\circ} \mathrm{C}$. The UV readings of the freshly prepared solutions were compared with the UV readings of the same solutions after 1 and $7 \mathrm{~d}$ in the storage conditions.

\section{Dog model of ischaemic ventricular tachycardia (VT) and ventricular fibrillation (VF)}

Six male mongrel dogs (24-35 kg) underwent a left thoracotomy and pericardiotomy under pentobarbital anaesthesia. A bipolar platinum electrode was placed on the left atrial appendage and pacing was carried out during each study at 180 beats/min using twice the diastolic capture threshold current. Surface electrodes and unipolar epicardial electrodes (on ischaemic and non-ischaemic zones of the left ventricle) were used for electrocardiogram recordings. The blood pressure and the pacing electrode signal were also recorded. Each animal was subjected to 5-hourly $10 \mathrm{~min}$ complete occlusions of the LAD followed by $50 \mathrm{~min}$ of normal perfusion. Five replicate occlusions were carried out to assure the reproducibility of arrhythmias in each dog before therapy. This dog model is a modification of the method described by Elharrar et al. ${ }^{27}$. In the current model, the hearts underwent a 10 min complete occlusion. as opposed to $6 \mathrm{~min}$ used by Elharrar et $a .^{27}$. To normalize the data, the numbers of premature beats (PM), doublets (DB) and ventricular tachycardia (VT) episodes were calculated per minute. One of the common consequences of the repeated occlusions was ventricular fibrillation (VF) either during the occlusion or with reflow. In the event of fibrillation during an occlusion, the occluder was released and the dog resuscitated with a DC defibrillator.

Arrhythmia episodes were counted during each occlusion period and during the intervening periods after the fourth and fifth occlusions. Two consecutive premature beats were defined as a doublet while three or more were defined as ventricular tachycardia. Immediately after the fifth occlusion a propranolol patch was put on the LAD ischaemic zone. After the patch was in place for an hour the last $10 \mathrm{~min}$ occlusion was carried out. Blood samples were collected from the femoral and regional coronary veins every $10 \mathrm{~min}$ during the drug study period. Before storage at $-20^{\circ} \mathrm{C}$ ascorbic acid (to a $5 \mathrm{mg} / \mathrm{ml}$ concentration) was added to the separated plasma to prevent propranolol oxidation ${ }^{28}$.

\section{Blood samples analysis}

Peripheral and coronary venous propranolol levels were measured using a modification of an HPLC method that was described by Abdel-Hamid ${ }^{28}$. To a $1 \mathrm{ml}$ aliquot of thawed peripheral plasma samples $100 \mu \mathrm{l}$ of internal standard solution (Quinidine, $10 \mu \mathrm{g} / \mathrm{ml}$ ), $1 \mathrm{ml}$ of a sodium hydroxide solution $(1.0 \mathrm{M}), 1 \mathrm{ml}$ of water and $5 \mathrm{ml}$ ether were added. After vortexing for $30 \mathrm{~s}$ and centrifuging for

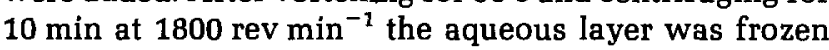
over an isopropranol-dry ice bath and the ethereal phase was separated. Then $200 \mu \mathrm{l} 0.1 \%$ phosphoric acid containing $5 \mathrm{mg} / \mathrm{ml}$ ascorbic acid were added to the ethereal phase, mixed, centrifuged and frozen. After discarding the ethereal layer the frozen pellets were thawed and $50 \mu \mathrm{l}$ were injected into the HPLC. From the thawed coronary plasma only $0.5 \mathrm{ml}$ aliquots were taken and $\mathrm{NaOH}(0.25 \mathrm{ml})$ and water $(0.25 \mathrm{ml})$ were added. A calibration curve was prepared in $1 \mathrm{ml}$ blank dog plasma containing $5 \mathrm{mg} / \mathrm{ml}$ ascorbic acid and was found to be linear in the range that was checked $(10-300 \mathrm{ng} / \mathrm{ml})$.

\section{Residual matrix drug detection}

Retrieved propranolol hydrochloride matrices in MPU-5 were extracted with methanol in a Soxhlet apparatus (Fisher Scientific). The extracts were analysed by HPLC (see later) and the net in vivo release was calculated.

\section{HPLC conditions}

An isocratic separation was achieved as follows: the mobile phase was prepared by combining $56 \mathrm{ml}$ phosphoric acid solution $(0.02 \mathrm{M}, \mathrm{pH} 4)$ with $28 \mathrm{ml}$ of acetonitrile and $16 \mathrm{ml}$ of methanol ${ }^{28}$. The flow rate was $1 \mathrm{ml} / \mathrm{min}$. A combination of $212 \mathrm{~nm}$ excitation filter and $340 \mathrm{~nm}$ emission filter were used for fluorescence detection. These conditions were used for quantitation of both the residual matrix propranolol after application and the blood samples.

\section{RESULTS}

\section{In vitro release}

Propranolol was previously found ${ }^{29}$ to be unstable at alkaline $\mathrm{pH}$. To be certain that propranolol was stable during the release study at $37^{\circ} \mathrm{C}$ and during storage at $4^{\circ} \mathrm{C}$, the slopes of the calibration curves were compared after storage at each temperature. The slope of the 'freshly prepared' calibration curve was not found to be significantly different from the slopes of the calibration curves of the solutions stored at 37 and $4^{\circ} \mathrm{C}$ after $1 \mathrm{~d}$ $\left(y=1.86 \times 10^{-2} x, 1.87 \times 10^{-2} x, 1.86 \times 10^{-2} x\right)$ or $7 \mathrm{~d}$ $\left(y=1.86 \times 10^{-2} x, 2.03 \times 10^{-2} x, 1.89 \times 10^{-2} x\right)$.

The release rates of propranolol from four different formulations were quantified and compared up to $10 \mathrm{~d}$ (Figure 1). While the polyurethane preparations were releasing most of the drug during the first day, the copolymer matrix released only about $15 \%$ of its content over $10 \mathrm{~d}$. When comparing the release up to $60 \mathrm{~min}$, which was the duration of the in vivo release up to the drug test occlusion it was found that the matrix that contained $30 \%$ propranolol hydrochloride in MPU-5 released $66.5 \pm 4.4 \%$ (mean $\pm S D$ ). However, the $20 \%$ 

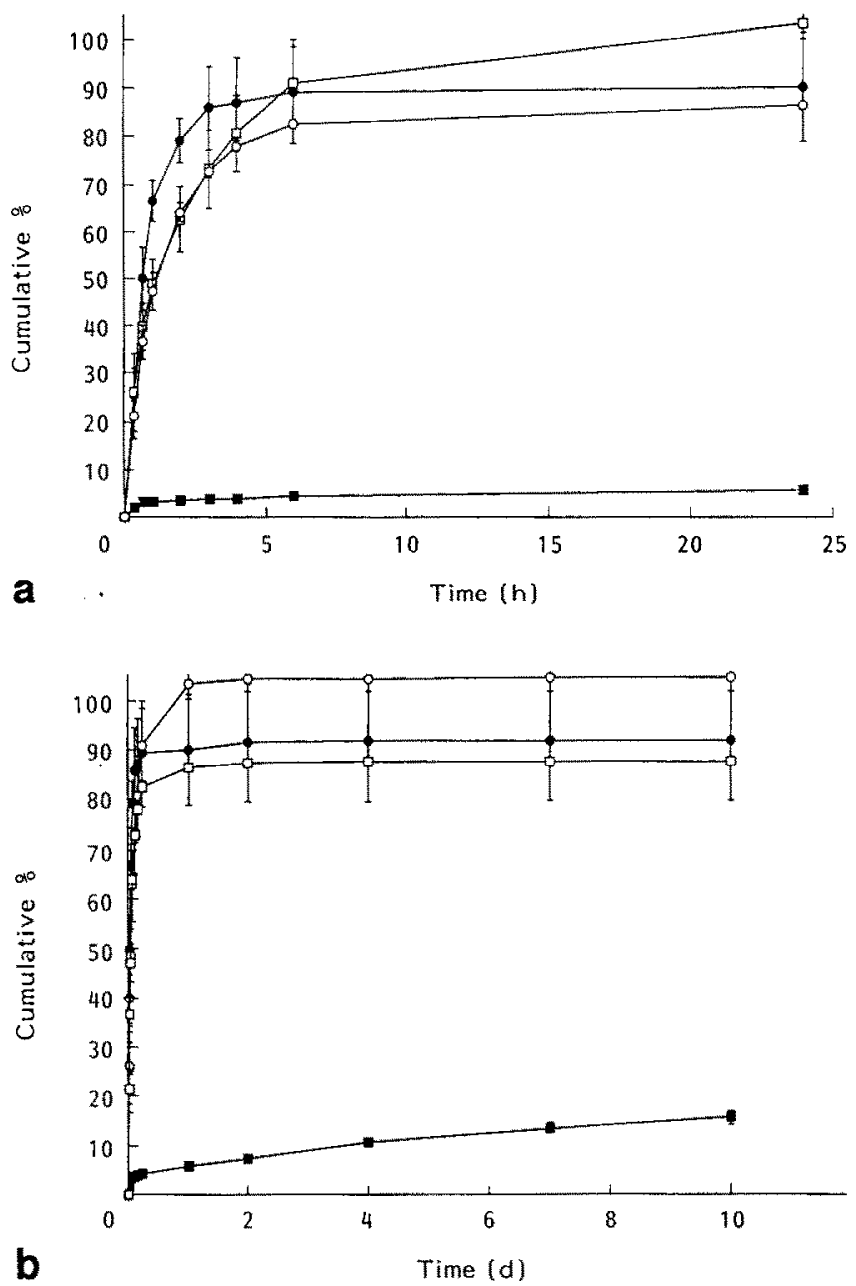

Figure 1 Propranolol in vitro release as cumulative percentage $\left(37^{\circ} \mathrm{C}, \mathrm{pH} 7.4\right)$ from $30 \%$ MPU-5 (口), $20 \%$ MPU-5 (๑), $20 \%$ polyurethane-silicone rubber copolymer ( $\mathrm{E}$ ) and $20 \%$ Biomer (O). a, $24 \mathrm{~h}, \mathrm{~b}, 10 \mathrm{~d}$.

propranolol loaded matrices in MPU-5, Biomer and the copolymer released $47.2 \pm 3.9 \%, \quad 48.7 \pm 5.5 \%$ and $3.25 \pm 0.3 \%$ respectively. Since the amount of drug released from the $30 \%$ MPU -5 matrices was significantly greater than the amount released from the $20 \%$ preparations in MPU-5 and Biomer $t=8.36, P=0.001$ and $t=6.81, P=0.002$ respectively) the matrix that contained $30 \%$ propranolol in MPU-5 was used for the in vivo studies.

\section{Arrhythmia experiments}

Dose

Following in vivo release $(70 \mathrm{~min})$ in the dogs, the drug matrices were extracted for residual propranolol content. It was found that $140 \pm 45 \mu \mathrm{g} / \mathrm{kg}$ of propranolol were delivered.

\section{Occlusion experiments}

Analyses of the frequency of the different types of ventricular arrhythmias, premature (PM), doublet (DB) and ventricular tachycardia (VT) beats during the occlusion periods and during the intervals following the fourth and fifth occlusions demonstrated that frequencies of each type of ventricular arrhythmia per minute during acute ischaemia were not significantly different with or without propranolol. VT frequencies (episodes per minute, mean \pm standard error) for occlusions 1 through 5 were $1.40 \pm 0.38,1.09 \pm 0.35,0.80 \pm 0.32,1.18 \pm 0.60$ and $1.34 \pm 0.49$ respectively. Following $1 \mathrm{~h}$ propranolol epicardial administration VT frequency was $1.02 \pm 0.31$. The results are summarized in Table 1 and Figure 2. To examine the proarrhythmic effect of propranolol, the interval following the fourth occlusion, before the drug matrix was sewn on, and the interval after the fifth occlusion. following the matrix placement, were compared. Although the frequency of PM beats, DB and VT per min was greater during the hour after propranolol was administered to the heart compared to the control the differences were not significant statistically $(P>0.5$, Student's $t$ test]. Propranolol also tended to reduce the mean blood pressure; the reduction was also not significant statistically $(P>0.5)$ compared to control. In addition, propranolol did not influence the onset of ventricular fibrillation.

\section{Peripheral versus coronary blood levels following epicardial propranolol}

Peripheral propranolol levels ranged from 8.7 to $43.7 \mathrm{ng} / \mathrm{ml}$, while simultaneous coronary blood levels were significantly elevated $(P<0.001)$ compared with peripheral levels, and ranged from 360.6 to $556.2 \mathrm{ng} / \mathrm{ml}$ [Figure 3], emphasizing the enhanced regional nature of epicardial controlled release therapy.

\section{DISCUSSION}

In the present study the in vitro release rate was found to be influenced by the nature of the polymer in which the drug was compounded. The release rate from MPU-5, the most hydrophilic polymer used in our investigation, was significantly higher than the release rate from the other polyurethane studied, Biomer, which is relatively less hydrophilic than MPU-5. Furthermore the release rate of propranolol from the copolymer 6605-41 which was the least hydrophilic polymer investigated, since it is a polyurethane-silicone rubber, was more sustained than noted with MPU-5 or Biomer. The same trend was previously found ${ }^{30}$ for the release of $\mathrm{FeCl}_{3}$ and $\mathrm{Al}\left(\mathrm{NO}_{3}\right)_{3}$ from Biomer and the copolymer 6605-41. The ability of these various polymer matrices to deliver a range of antiarrhythmic drug doses over prolonged periods of time is of particular importance; for an acute arrhythmia a higher dose for a short period of time might be needed, while for maintenance of an inhibitory drug level for chronic arrhythmia therapy a lower dose over a long period of time might be needed.

The propranolol coronary blood levels were also shown to be up to 50 times greater than the peripheral levels. This result emphasizes the propensity for epicardial controlled release to achieve regionally high drug levels while minimizing the magnitude of systemic blood levels. The same phenomenon was demonstrated when either lidocaine $e^{9}$ or procainamide ${ }^{10}$ were administered to the heart by controlled release matrices. Plasma propranolol levels of up to $1000 \mathrm{ng} / \mathrm{ml}$ may be required to control resistant ventricular arrhythmias based on clinical results ${ }^{4}$. However, only $25 \%$ of the usual 
Table 1 Comparison of frequencies of arrhythmic episodes, time to VF and blood pressure with and without propranolol*

\begin{tabular}{|c|c|c|c|c|}
\hline & $\begin{array}{l}\text { Control } \\
\text { (1st to 5th } \\
\text { occlusions combined) }\end{array}$ & Propranolol & 4th reflow & 5th reflow \\
\hline $\begin{array}{l}\text { Occlusions }(n) \\
\text { PM/min } \\
\text { DB/min } \\
\text { VT/min } \\
\text { Time to VF (min) } \\
\text { Mean BP (mmHg) }\end{array}$ & $\begin{array}{l}30 \\
2.5 \pm 0.68^{\star} \\
0.75 \pm 0.31 \\
1.22 \pm 0.12 \\
5.28 \pm 0.48 \\
153.6 \pm 6.5\end{array}$ & $\begin{array}{r}6 \\
2.64 \pm 0.69 \\
0.69 \pm 0.14 \\
1.02 \pm 0.31 \\
5.38 \pm 0.86 \\
131.3 \pm 16.5\end{array}$ & $\begin{array}{l}6 \\
0.10 \pm 0.06 \\
0.03 \pm 0.03 \\
0.02 \pm 0.01 \\
- \\
-\end{array}$ & $\begin{array}{l}6 \\
0.46 \pm 0.27 \\
0.26 \pm 0.14 \\
0.07 \pm 0.05 \\
- \\
-\end{array}$ \\
\hline
\end{tabular}

Data are mean \pm sem.

PM, premature; DB, doublet; VT, ventricular tachycardia; VF, ventricular fibrillation; BP, blood pressure.

antiarrhythmic dose, $140 \mu \mathrm{g} / \mathrm{kg}$, was needed to achieve a nearly maximal therapeutic level in the coronary blood in the present study. Also, according to our results, when propranolol was given locally the peripheral drug levels were within the low end of the therapeutic range for

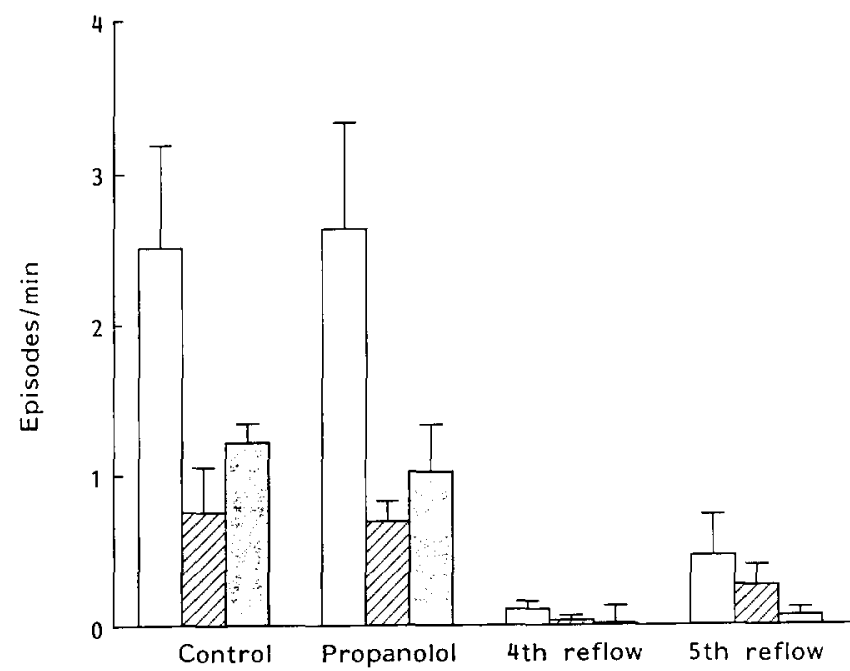

Figure 2 Frequency of arrhythmia episodes with and without propranolol during occlusion and reflow. Isolated premature beats $(\square)$, doublets $(\square)$, ventricular tachycardia $(\square)$

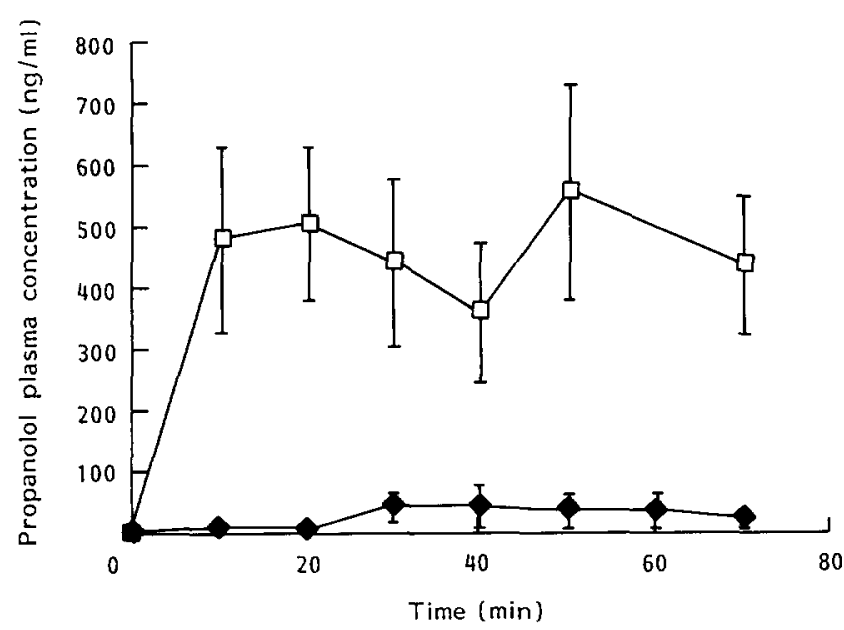

Figure 3 Propranolol plasma levels $(\mathrm{ng} / \mathrm{ml}$, means \pm standard errors). Coronary ( $\square$ ), peripheral (๑). treating angina and hypertension based on clinical studies $^{4}$

Although propranolol epicardial administration resulted in significantly higher blood levels in the heart compared with the peripheral blood, no significant antiarrhythmic effect was demonstrated. Furthermore, peripheral plasmapropranolol levels were also in the therapeutic range relative to clinical data concerning both arrhythmia therapy and hypertensions ${ }^{20-22,31}$. Prior animal and clinical studies have also demonstrated that systemic propranolol reduces the occurrence of ventricular arrhythmias due to myocardial ischaemia ${ }^{20-22,24-26}$ or infarction ${ }^{1,4}, 5,17,20$. Furthermore, systemic administration of propranolol by others has been effective in dog models of ischaemia comparable to ours ${ }^{24-26}$ and also infarctionrelated arrhythmias using net total dosages comparable to those used in the present study ${ }^{20}$. These prior studies cannot be viewed as providing systemic drug administration of relevance for the present experiments. Thus, additional drug protocols in the present series of studies could have compared an array of systemic dosages of propranolol to the epicardial results. However, the lack of any antiarrhythmia activity with epicardial controlled release compared to non-drug coronary occlusions, despite near maximal coronary venous drug concentrations, and systemic hypotension obviates the usefulness of further studies along these lines. Furthermore, a relevant systemic dose for comparisons with the epicardial studies might have involved giving the same dose administered by the matrix intravenously over $1 \mathrm{~h}$, or administering an appropriate intravenous dose based on pharmacokinetic parameters to achieve a systemic or coronary propranolol level identical to that achieved with epicardial administration. Other treatment groups could also have considered regional intracoronary injection of propranolol or coronary venous retroperfusion, again to obtain coronary venous plasma levels identical to those achieved with a matrix. These other administration variations were beyond the scope of this study but may be worth further consideration.

In addition the present results suggest that while systemic $\beta$-blockade may be effective for ventricular arrhythmias this is likely be due to central effects rather than directly influencing cardiac $\beta$-adrenergic activity. Alternatively, D-propranolol for suppression of ventricular arrhythmias in man has recently been shown to be as effective as the racemic preparation ${ }^{32}$, thereby demonstrating that propranolol's efficacy for ventricular arrhythmias may not be entirely related to its $\beta$-blocking. 
Table 2 Comparisons of epicardial polymeric (polyurethane) controlled release therapy: results of acute ischaemia-ventricular tachycardia (VT) studies in dogs ${ }^{\mathrm{a}}$

\begin{tabular}{|c|c|c|c|c|c|c|}
\hline Drug & Class $^{b}$ & Mechanisms & Loading & $\begin{array}{l}\text { Dose } \\
(\mathrm{mg} / \mathrm{kg} / 2 \mathrm{~h})\end{array}$ & $n$ & $\begin{array}{l}\text { VT } \\
\text { (per/min) }\end{array}$ \\
\hline $\begin{array}{l}\text { Lidocaine } \\
\text { Propranolol } \\
\text { D-Sotalol } \\
\text { Verapamil } \\
\text { No therapy }\end{array}$ & $\begin{array}{l}\text { I } \\
\text { II } \\
\text { III } \\
\text { IV } \\
-\end{array}$ & $\begin{array}{l}\text { Na channel blockade } \\
\beta \text {-blocker } \\
\text { Delayed repolarization } \\
\text { Calcium channel blocker } \\
\text { - }\end{array}$ & $\begin{array}{l}28 \% \\
30 \% \\
30 \% \\
30 \% \\
-\end{array}$ & $\begin{array}{l}0.23 \\
0.14 \\
0.20 \\
0.30 \\
-\end{array}$ & $\begin{array}{r}5 \\
6 \\
9 \\
11 \\
9\end{array}$ & $\begin{array}{l}0.6 \pm 0.2 \\
1.22 \pm 0.12 \\
0.46 \pm 0.11 \\
0.10 \pm 0.03 \\
1.10 \pm 0.30\end{array}$ \\
\hline
\end{tabular}

${ }^{a}$ Modified from Levy ef al, in Cosmetic and Pharmaceutical Application of Polymers, Plenum, NY, USA, 1991, pp 231-238.

${ }^{b}$ Vaughan Williams classification ${ }^{15}$.

Therefore, propranolol's failure to affect ventricular arrhythmias via epicardial administration may be due to complex and incompletely understood factors.

The tendency observed in the present studies for epicardial propranolol to reduce blood pressure and to intensify arrhythmias during non-ischaemic periods was not found to be statistically significant. Nevertheless, this possible $\beta$-adrenergic antagonist effect might be better investigated in further experiments planned with sotalol. Sotalol, a relatively new antiarrhythmic drug, has two active stereoisomers. The L-isomer has $\beta$-blocker activity, while $D$-sotalol is classified as a class III antiarrhythmic drug ${ }^{33}$. Thus, experiments with each of the isomers and with the racemic mixture might be most useful for further studying the importance of $\beta$-blockers for antiarrhythmia therapy.

Despite the lack of effectiveness of epicardial controlled release propranolol in this ischaemic ventricular arrhythmia model system, virtually all the other classes of antiarrhythmic agents have been shown to be effective for decreasing the occurrence ischaemic arrhythmias in this dog model when administered by epicardial controlled release matrices $(\text { Table } 2)^{34}$. Thus, further research investigating myocardial $\beta$-blockade via epicardial controlled release may not prove to be as fruitful as other mechanistic strategies.

\section{CONCLUSIONS}

Propranolol, serving as a model $\beta$-adrenergic antagonist, was successfully delivered from a polyurethane matrix placed on the left ventricular epicardium in dogs. Although potentially therapeutic blood levels were achieved both in the heart and in the periphery, epicardial propranolol, while causing mild hypotension, failed to prevent ventricular arrhythmias due to acute ischaemia. Thus it was not found to be useful as a treatment for ventricular arrhythmias due to acute ischaemia in a dog model system.

\section{ACKNOWLEDGEMENT}

The authors thank Mrs Catherine Wongstrom for her assistance with the manuscript. This research was supported by NIH Grant HL41663 and American Heart Association Grant-in-Aid 890654.

\section{REFERENCES}

1 Curtis, A.B. and Mansour, M., New approaches to management of arrhythmias after myocardial infarction, Cardiovasc. Clin. 1989, 20, 259-281

2 Chakko, S., De Marchena, E., Kessler, K.M. and Myerburg, R.J., Electrophysiology, pacing, and arrhythmia ventricular arrhythmias in congestive heart failure, Clin. Cardiol. 1989, 12, 520-530

3 Liem, L.B. and Kates, R.E., Update: cardiac antiarrhythmic drugs, Compr. Thesr. 1989, 15, 17-27

4 Bigger, J.T. Jr and Hoffman, B.F., Antiarrhythmic drugs, in The Pharmacolugical Basis of Therapeutics (Eds A.G. Gilman, L.S. Goodman, T.W. Rall and F. Murod), Macmillan, NY, USA, 1985, pp 748-783

5 Podrid, P.J., Antiarrhythmic drug therapy - benefits and hazards, Chest 1985, 88, 453-460

6 McCollam, P.L., Parker, R.B., Beckman, K.J., Hariman, R.J. and Bauman, J.L., Proarrhythmia: a paradoxic respionse to antiarrhythmic agents, Pharmacotherapy 1988, 9, 144-153

7 Tisdale, J., Combination antiarrhythmic therapy, Community Med. 1989, 53, 101-105

8 Sintov, A., Scott, W., Dick, M. and Levy, R.J., Cardiac controlled release for arrhythmia therapy: lidocaine polyurethane matrix studies, J. Controlled Rel. 1988, 8, 157-165

9 Sintov, A., Scott, W.A., Siden, R. and Levy, R.J., Efficacy of epicardial controlled-release lidocaine on ventricular tachycardia induccd by rapid ventricular pacing in dogs, J. Cardiovasc. Pharmacol. 1990, 16, 812-817

10 Siden, R., Sintov, A. and Levy, R.J., Epicardial drug administration with controlled release matrices for ventricular arrhythmias, Proc. Int. Symp. Controlled Rel. Bioact. Mater. 1989, 16, 493-494

11 Siden, R., Flowers, W., Kadish, A.H. and Levy, R.J., Prevention of ventricular tachycardia/fibrillation due to acute ischemia with epicardial verapamil, Pharm. Res. 1989, 6, S-97A

12 Olanof, L.S., Anderson, J.M. and Jones, R.D., Sustained release of gentamicin from prosthetic heart valves, Trans. Am. Soc. Artif. Intern. Organs 1979, 25, 334338

13 Munksgaard, K. and Terpstra, B., Acute and long-term atrial and ventricular stimulation thresholds with a steroid-eluting electrode, PACE 1985, 8, 45-49

14 Levy, R.J., Wolfrum, F.J., Schoen, F.J., Hawley, M.A., Lund, S.A. and Langer, R., Inhibition of calcification of bioprosthetic heart valves by local controlled-release diphosphonate, Science 1985, 228, 190-192

15 Vaughan Williams, E.M., A classification of antiarrhythmic actions reassessed after a decade of new drugs, J. Clin. Pharmacol. 1984, 24, 129-147

16 Physician's Desk Reference 1988, 42, 648-650 
17 Beta-Blocker Heart Attack Study Group. The beta blocker heart attack trial, JAMA 1981, 246, 20732074

18 Morganroth, J., Antiarrhythmic effects of beta-adrenergic blocking agents in benign or potentially lethal ventricular arrhythmias, Am. J. Cardiol. 1987, 60, 100-140

19 Brodsky, M.A., Allen, B.J., Luckett, C.R., Capparelli, E.V., Wolff, L.J. and Henry, W.L., Antiarrhythmic efficacy of solitary beta-adrenergic blockade for patients with sustained ventricular tachyarrhythmias, Am. Heart J. 1989, 118, 273-280

20 Coltart, D.J. and Shand, D.G., Plasma propranolol levels in the quantitative assessment of beta-adrenergic blockage in man, Br. Med. J. 1970, 3, 731-734

21 Podrid, P.J., Fuchs, T. and Candinas, R., Role of the sympathetic nervous system in the genesis of ventricular arrhythmia, Circulation 1990, 82 (suppl. 2), I102113

22 Coumel, P., Leclerq, J.F. and Zimmerman, M., The clinical use of beta-blockers in the prevention of sudden death, Eur. Heart J. 1986, 7 (suppl. A), 187-201

23 Gang, E.S., Bigger, J.T, and Uhl, E.W., Effects of timolol and propranolol on inducible sustained ventricular tachyarrhythmias in drugs with subacute myocardial infarction, Am. J. Cardiol. 1984, 53, 275-281

24 Hope, R.R., Williams, D.D., El-Sherif, N., Lazzara, R, and Scherlag, B.J., The efficacy of antiarrhythmic agents during acute myocardial ischemia and the role of heart rate, Circulation 1974, 50, 507-514

25 Kupersmith, J., Shiang, J., Litwak, R.S. and Herman, M.V., Electrophysiological and antiarrhythmic effects of propranolol in canine acute myocardial ischemia, Circ. Res. 1976, 38, 302-307

26 Ogawa, T., Nobuyuki, H., Sugiyama, S., Ito, T., Satake, $\mathrm{T}$. and Ozawa, T., Cardioprotective and antiarrhythmic effects of beta-blockers, propranolol, bisoprolol, and nipradilol in a canine model of regional ischemia, Heart Vessels 1989, 5, 10-16

27 Elharrar, V., Gaum, W.E. and Zipes, D.P., Effect of drugs on conduction delay and incidence of ventricular arrhythmias induced by acute coronary occlusion in dogs, Am. J. Cardiol. 1977, 39, 544-549

28 Abdel-Hamid, M.E., High-performance liquid chromatographic determination of propranolol and 4-hydroxypropranolol in serum, J. Clin. Pharm. Ther. 1988, 13, 183-189

29 Rooney, M. and Creurer, I., Stability of propranolol hydrochloride suspension and solution, I. Hosp. Pharm. 1988, 45, 530-531

30 Pathak, Y.V., Boyd, J., Schoen, F.J. and Levy, R.J., Prevention of calcification of glutaraldehyde pretreated bovine pericardium through controlled release polymeric implants: studies of $\mathrm{Fe}^{+3}, \mathrm{Al}^{+3}$, protamine sulfate and levamisole, Biomaterials 1990, 11, 718-723

31 Frishman, W.H., Laifer, L.I. and Furberg, C.D., Betaadrenergic blockers in the prevention of sudden death, Cardiovasc. Clin. 1985, 15, 249-264

32 Murray, K.T., Reilly, C., Koshakji, R.P., Roden, D.M. Lineberry, M.D., Wood, A.J., Siddoway, L.A., Barbey, J.T. and Woosley, R.L., - Suppression of ventricular arrhythmias in many by $\mathrm{D}$-propranolol independent of beta-adrenergic receptor blockage, J. Clin. Invest. 1990 85, 836-842

33 Sahar, D.I., Reiffel, J.A. and Bigger, J.T., Efficacy, safety, and tolerance of $\mathrm{D}$-sotalol in patients with refractory superventricular tachyarrhythmias, Am. Heart J. 1989 , 117, 562-568

34 Levy, R.J., Bolling, S.F., Siden, R., Kadish, A., Pathak, Y., Dorostkar, P., Sintov, A., Golomb, G. and Johnston, T.P., Polymeric controlled release of cardiovascular drugs, Cosmetic and Pharmaceutical Applications of Polymers (Ed. C. Gebelein), Plenum, NY, USA, 1991, pp 231-238

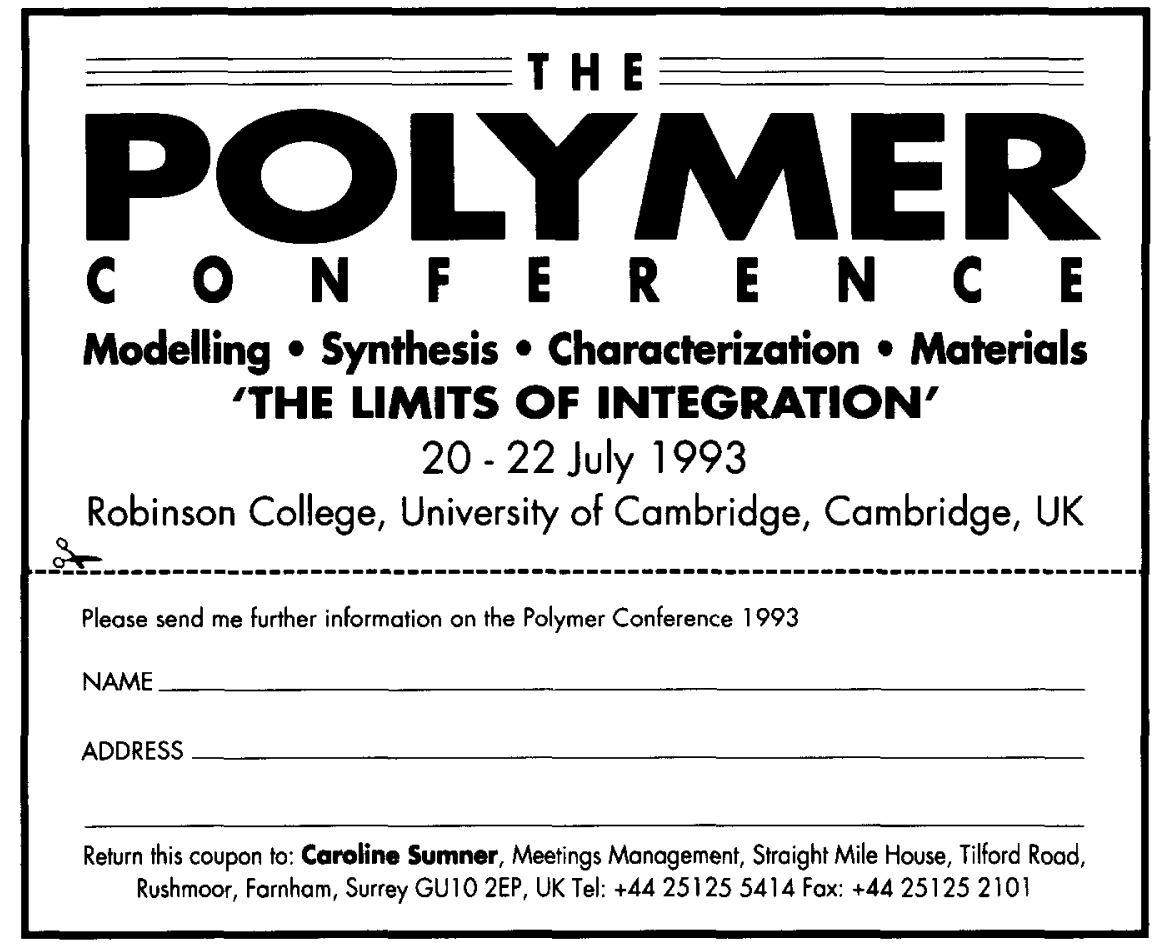

Biomaterials 1992, Vol. 13 No. 11 